\title{
Comparação de osteossíntese com placa e osteossíntese com placa associada a enxerto de proteína morfogenética óssea em fratura bilateral distal de rádio e ulna em cão - Relato de Caso
}

Marcos Ishimoto DELLA NINA $^{1}$

Alexandre SCHMAEDECKE ${ }^{1}$ Leandro ROMANO ${ }^{1}$

Cássio Ricardo Auada FERRIGNO ${ }^{1}$

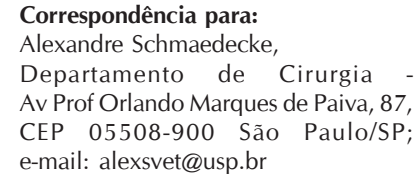

Correspondência para: Alexandre Schmaedecke, Departamento de Cirurgia Av Prof Orlando Marques de Paiva, 87, CEP 05508-900 São Paulo/SP; e-mail: alexsvet@usp.br

Recebido para publicação: 06/03/2006 Aprovado para publicação: 05/03/2007
1- Departamento de Cirurgia da Faculdade de Medicina Veterinária e

Zootecnia da Universidade de São Paulo, São Paulo - SP

\author{
Palavras-chave: \\ Proteínas morfogenéticas ósseas. \\ Rádio (anatomia). \\ Ulna. \\ Cães. \\ Fixação interna de fraturas.
}

fraturas distais, relacionadas a características anatômicas inerentes, como pouco recobrimento de tecido muscular, canal medular de diâmetro reduzido, e pouca vascularização. Tendo em vista esta realidade, descreve-se a comparação entre o tratamento com placa e parafuso e placa e parafuso com adição de proteína morfogenética óssea em fratura completa transversa de terço distal bilateral de rádio-ulna, de semelhante apresentação em cão da raça Pinscher, atendido no Serviço de Cirurgia de Pequenos Animais do HOVET/ USP. Avaliou-se, comparativamente, o tempo de formação de calo ósseo, por exames radiográficos, aos 30, 60, 90 e 120 dias de pósoperatório, onde foi encontrado tempo de cicatrização de 90 dias no membro controle enquanto que, no membro tratado com a proteína morfogenética óssea, o tempo de cicatrização foi de 30 dias, demonstrando a possibilidade de incremento que o uso de fatores de crescimento podem trazer ao tratamento de fraturas em cães de pequeno porte.

\section{Introdução e Revisão da Literatura}

As fraturas de rádio-ulna constituem de $8,5 \%$ a $10,7 \%$ de todas as fraturas que acometem os cães e gatos. Apenas um ou os dois ossos do membro locomotor torácico podem estar fraturados em apenas um local ou com fraturas múltiplas combinadas. As fraturas de rádio-ulna são consideradas o terceiro tipo de fratura mais comum nos cães ${ }^{1,2}$.

Os tratamentos das fraturas destes ossos são considerados dificultosos por alguns autores, levando muitas vezes à nãounião ou má-união, causando desvios e incongruências ósseas, com efeitos maléficos à marcha do animal $13,4,5,6$.

Certas características inerentes a estas estruturas, como pouco recobrimento de tecido muscular, canal medular de diâmetro reduzido ou pouca vascularização são as causas principais de complicações, sejam após intervenções cirúrgicas ou em tratamentos conservadores $1,3,4,5,6,7,7,9,9$.

$O$ fator racial tem influência nas aludidas complicações. Nas raças grandes ou gigantes, o peso calcado no local da fratura e no material de fixação é grande $e^{1,3,7,8,9}$. Já nas raças pequenas, existem trabalhos relatando até $60 \%$ de não-união óssea, causada geralmente pela ineficiente vascularização ${ }^{6}$.

O rádio é o osso no qual se deposita a maior parte do peso sustentado pela região distal do membro torácico. Articula-se distalmente com os ossos carpo radial e carpo ulnar e em sua porção proximal com o côndilo lateral do úmero. Estas características anatômicas, aliadas à sua forma, tornam-no 
osso contra-indicado para a colocação de pinos intramedulares, mas facilitam a utilização de placas, por seu córtex cranial quase plano, e de fixadores externos, pela facilidade de abordagem nos planos lateral e medial ${ }^{1,3,4,8,9}$.

Há muito que se buscam novas alternativas para se estimular a formação óssea, não somente nos casos de fraturas com grandes perdas de tecido ósseo, mas também em casos de malformação e correções posturais $^{10-18}$.

O processo de consolidação óssea é forma especializada de reparo de lesão onde existe regeneração do tecido lesado sem a formação de cicatrizes. O processo envolve etapas de crescimento ósseo, modelamento e remodelamento ${ }^{19}$.

Imediatamente após a fratura ocorre a fase de resposta aguda onde o organismo, através do processo inflamatório local, provoca mudança na concentração de algumas proteínas circulantes como proteínas de coagulação, de transporte e inibidoras e, também, algumas modificações hormonais como níveis de insulina, glicocorticóides, catecolaminas além de algumas mudanças nos níveis de vitaminas e minerais como zinco e ferro ${ }^{19}$.

O acompanhamento da consolidação de fratura é baseada tanto na evolução clínica como através de exames complementares como o radiológico. Normalmente, os achados radiográficos podem variar de acordo com alguns fatores como idade do paciente, método empregado no reparo e estabilização da fratura, tipo de fratura e grau de lesão concomitante de tecidos moles ${ }^{19}$.

Os primeiros 15 dias de pósoperatório devem ser o período onde são observadas as mudanças em tecidos moles e o início de sinais de estabelecimento de infecções pós-operatórias. No período de quatro a seis semanas após o ato cirúrgico, a cicatrização da fratura já deve indicar avanço significativo, o calo ósseo já pode ser visível e as falhas de implantes normalmente já serão notadas neste período.

A consolidação óssea sob condições estáveis é observada quando são utilizadas as técnicas de placas e parafusos, que auxiliam na ausência de movimentação no foco de fratura. Este tipo de reparo é chamado de união primária ou união direta. Durante o pós-operatório imediato podem ser observados nos tecidos moles linhas pequenas ou finas de ar, causadas pelo procedimento cirúrgico, tendendo a desaparecer em um ou dois dias. As linhas de fratura mantêm-se inalteradas durante o período de uma a duas semanas. Segundo a literatura, isto deve-se a perda inicial de irrigação sangüínea, sendo necessário um certo período de tempo para a recuperação da vascularização local. Após um período de oito a 12 semanas, o desenvolvimento ósseo no foco de fratura é observado através de gradativa perda de nitidez da linha de fratura. A linha de fratura tende a desaparecer dentro de alguns meses ${ }^{20}$.

BMP é a sigla utilizada para a denominação inglesa "Bone Morphogenetic Proteins", descrito primeiramente por Urist 21. Urist ${ }^{21}$ notou a formação de osso heterotópico após a implantação de matriz óssea desmineralizada em pontos intramusculares. A seqüência de eventos observados foi idêntica ao observado durante a ossificação endocondral e na consolidação óssea. Nelas, as células mesenquimais indiferenciadas migram para o local de implantação onde ocorre proliferação; os condroblastos derivados das células mesenquimais secretam componentes da matriz extracelular para formar a base cartilagínea. Esta base é hipertrofiada e a matriz extracelular torna-se vascularizada por células hematopoiéticas e endoteliais. Em seguda, ocorre o aparecimento de osteoblastos e osteoclastos, quando haverá reabsorção da cartilagem e sua substituição por osso.

As proteínas morfogenéticas ósseas são estruturas que fazem parte da grande familia de fatores de crescimento conhecidos como TGF ("transforming growth factors") que englobam um conjunto de proteinas, cada qual com sua composição e efeito biológico, atuando em sítios específicos de tecidos variados, porém o BMP é fator de 
crescimento conhecido que provoca formação de osso heterotópico por meio da diferenciação de células mesenquimais indiferenciadas em osteoblastos e condroblastos, sem provocar aumento na atividade mitótica celular. Portanto, o BMP atua de duas formas: provocando quimiotaxia de células indiferenciadas para o local da implantação e na diferenciação destas em células responsáveis pela produção de matriz óssea ${ }^{22,23}$.

A habilidade do BMP de induzir osteogênese é influenciada por vários fatores, como a fonte e o potencial osteoindutivo da preparação do BMP, a viabilidade e habilidade morfogenética óssea ou a capacidade de resposta à indução das células osteoprogenitoras do hospedeiro e das condições do ambiente local de implantação ${ }^{24}$.

\section{II - CASO CLÍNICO}

Descreve-se neste relato a fixação óssea com o uso de placa e parafusos em fratura bilateral distal de rádio e ulna em cão da raça Pinscher, de um ano de idade, com $4,0 \mathrm{~kg}$ de peso, com o uso concomitante de proteína morfogenética óssea em um dos membros afetados, avaliando-se comparativamente suas implicações sobre a evolução do processo de formação de calo ósseo até a completa consolidação da fratura.

\section{Conduta Operatória}

$\mathrm{O}$ animal foi tratado com cefalexina na dose de $20 \mathrm{mg} / \mathrm{kg}$, duas vezes ao dia, a partir de dois dias antes do ato cirúrgico.

Em relação às osteossínteses, após depilação e preparo rotineiro de campo operatório, foi realizada incisão cutânea na face crânio medial da região distal do rádio e ulna. A seguir, foi efetuada a divulsão dos tecidos subjacentes, localização, isolamento e afastamento dos tendões dos músculos extensor carpo-ulnar e extensor digital lateral e dos músculos extensor longo dos dedos e da cabeça ulnar do músculo flexor digital profundo. Foram iniciados, então, os procedimentos de redução e alinhamento dos fragmentos da fratura. Terminada esta etapa operatória, iniciou-se a técnica de colocação de placa e parafusos ósseos. No membro esquerdo, foi adicionado ao foco de fratura, $1,5 \mathrm{cc}$ da proteína morfogenética óssea (indutor e aglutinante de colágeno BMP - Baumer S.A.), tendo como carreador, osso liofilizado bovino e colágeno. A sutura dos planos cirúrgicos foi realizada segundo os padrões cirúrgicos consagrados (musculatura, tecido celular subcutâneo e pele por pontos simples separados, com utilização de fio de náilon monofilamento). Após o término dos procedimentos, os membros foram imobilizados com bandagens de Robert Jones.

\section{Procedimentos de Avaliação}

Para a avaliação dos resultados, adotou-se estudo temporal aos 30, 60, 90 e 120 dias de pós-operatório.

\section{Avaliação Clínica}

O animal foi observado com objetivos voltados ao estudo da evolução clínica pósoperatória. Foram observadas as estabilidades dos focos de fraturas pela palpação do membro, aumento de volume e dor na região, como também a utilização do membro na movimentação.

Quanto à consolidação completa do foco de fratura, verificou-se a funcionabilidade do membro operado. Para isto, foi observado o comportamento de cada membro com o animal em posição quadrupedal e em movimento. A fim de possibilitar padronização dos resultados, esses foram divididos em três graus: o grau I de funcionabilidade foi denominado como "impotência" e indicava que o animal não apoiava o membro operado em nenhum momento durante o exame clínico; o grau II foi denominado como "regular" e indicava que o não apoiava o membro em estação, mas quando exigido apoiava normalmente; o grau III foi denominado "boa" e indicava que o membro operado era apoiado normalmente, tanto em estação como em movimento.

\section{Avaliação Radiológica}

Nos devidos tempos de observação 
(30, 60, 90 e 120 dias), o animal foi submetido a exames radiográficos para avaliação do tempo de formação do calo ósseo. Em cada exame foram realizadas sempre duas vistas ortogonais do membro operado para melhor visibilização da evolução do calo ósseo. $\mathrm{O}$ animal não foi submetido à sedação ou anestesia durante os exames radiográficos.

\section{Resultados}

Foram observados e avaliados durante a execução deste tratamento, o tempo para a completa união óssea, a funcionabilidade de cada membro operado, as complicações que ocorreram durante o período de avaliação e dados relativos à idade, peso e tipo de fratura do animal da raça Pinscher, atendido no Serviço de Cirurgia de Pequenos Animais do Hospital Veterinário da Universidade De São Paulo (HOVET/USP).

Durante o período de observação do caso (120 dias), não houve qualquer complicação que possa ter influenciado no tempo de cicatrização óssea.

A funcionabilidade tanto do membro em que se utilizou somente placa e parafusos (direito), quanto daquele onde foi adicionada Proteína Morfogenética Óssea (esquerdo) apresentaram movimentação considerada boa a partir do décimo dia pós-cirúrgico.

Em relação ao tempo de união óssea, analisados através de exames radiográficos, o membro em que se utilizou Proteína Morfogenética Óssea apresentou consolidação em 30 dias (Figura 1), sendo que, no membro em que se utilizou apenas estabilização com placa e parafusos, não havia sinal de consolidação no mesmo período (Figura 2), sendo o tempo de consolidação total de 90 dias.

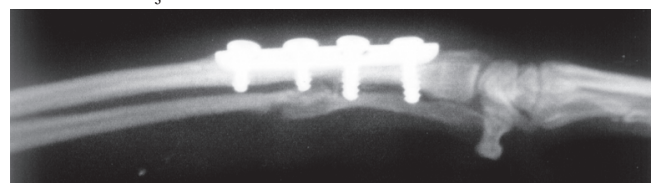

Figura 1 - Imagem radiográfica de rádio e ulna esquerdos de cão da raça Pinscher, submetido a osteossíntese com placa e parafusos, adicionado de enxerto de proteína óssea morfogenética, visibilizando consolidação óssea após 30 dias de procedimento cirúrgico.

\section{Discussão}

$\mathrm{Na}$ rotina de ortopedia veterinária de pequenos animais, os diversos tipos de fraturas de rádio e ulna são considerados traumatismos comuns $s^{1,3,4,7,8,9,19}$. Porém, em muitos casos, principalmente em animais de raças pequenas, as fraturas em porções distais de rádio e ulna apresentam alta porcentagem de não-união óssea, causada principalmente pela baixa vascularização da região ${ }^{6}$.

O animal foco deste relato, excetuando-se pela fratura bilateral de rádio e ulna, foi considerado hígido, tornando-o apto a responder de forma rápida e eficiente ao processo de consolidação do foco de fratura como mostra o trabalho de Skerry ${ }^{19}$, principalmente pelo fato de estar em faixa etária fora do período considerado como geriátrico por Goldston ${ }^{25}$, que para cães até $9 \mathrm{~kg}$ é de 11,48 $\pm 1,85$ anos. Nesta faixa etária ocorre redução da capacidade de quimiotaxia, na imunocompetência, fatores importantes para a atuação da proteína morfogenética óssea, além da taxa metabólica e perda gradativa de tecido ósseo, fatores que influenciariam em ambos os membros.

O fato do cão ter iniciado a movimentação com ambos os membros no mesmo período, demonstrou que o método de estabilização com placa e parafusos atuou de forma satisfatória nos dois membros operados, permitindo a atuação das forças de rotação, arqueamento, tração e compressão de forma semelhante em ambos os implantes, fato este que reduz a possibilidade de diferença de peso atuante em cada membro que segundo Bellah ${ }^{3}$, Denny $^{7}$, Egger ${ }^{8}$ e Turner ${ }^{9}$ pode levar a complicações na cicatrização óssea devido à maior força axial que é absorvida pelo

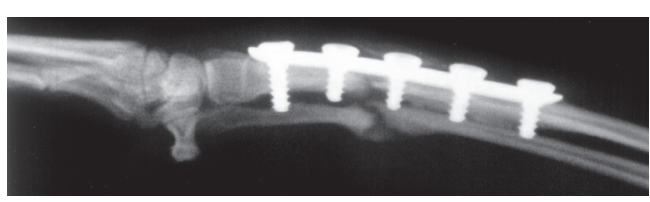

Figura 2 - Imagem radiográfica de rádio e ulna direitos de cão da raça Pinscher, submetido a osteossíntese com placa e parafusos, visibilizando solução de continuidade após 30 dias de procedimento cirúrgico. 
implante e foco de fratura, causando maior movimento dos fragmentos ósseos, como também falha do método de fixação óssea.

Não obstante a esta afirmação, Sumner-Smith e Cawley ${ }^{5}$, De Angelis, Olds e Stoll, Lappin et al. ${ }^{1}$, Vaughan ${ }^{6}$, Bellah ${ }^{3}$, Denny ${ }^{7}$, Egger ${ }^{8}$ e Turner ${ }^{9}$ relataram que animais pequenos apresentam dificuldade de consolidação causada por fatores como pouco recobrimento muscular, canal medular de diâmetro reduzido e principalmente pouca vascularização óssea em porções distais de rádio e ulna. Fato este que, por se tratar de animal onde foi empregado a mesma técnica de estabilização em ambos os membros, pode-se considerar como fator de pouca interferência nos resultados observados.

No tocante ao tempo de consolidação óssea do membro em que se utilizou a proteína morfogenética óssea, foi observado tempo menor de formação de calo ósseo. Este resultado foi influenciado pelas características osteogênicas da proteína morfogenética óssea, como mostraram os trabalhos de Ekelund, Brosjo e Nilsson ${ }^{24}$ que relataram a indução de células osteoprogenitoras do hospedeiro e Forell e Straw ${ }^{22}$ e Lind, Eriksen e Bunger ${ }^{23}$ que relataram a quimiotaxia e diferenciação de células indiferenciadas em células produtoras de matriz óssea.

Apesar do resultado precoce de cicatrização óssea encontrado, o membro contralateral, onde não se utilizou a proteína morfogenética óssea, apresentou valor semelhante de tempo de formação de calo ósseo aos descritos na literatura que, na idade do animal descrito, é de três meses a um ano para esta técnica de fixação com placas ósseas ${ }^{26}$.

Os resultados observados neste relato indicaram que o tipo de enxerto utilizado conseguiu reduzir significativamente o tempo de consolidação óssea em fraturas distais de rádio-ulna neste cão da raça Pinscher. Os valores encontrados de tempo de consolidação no membro em que se utilizou o enxerto contrastam visivelmente com os resultados observados no membro em que não se utilizou a proteína morfogenética óssea, demonstrando o significativo efeito que este promove nos focos de fraturas de rádio e ulna, reduzindo o tempo de consolidação, tornando a proteína morfogenética óssea uma poderosa e interessante ferramenta para auxiliar o médico veterinário ortopedista em acelerar e melhorar o restabelecimento pleno das funções de seu paciente no pós-operatório.

\section{Conclusão}

A partir dos resultados obtidos com o estudo comparativo entre a osteossíntese com placa e osteossíntese com placa associada a enxerto de proteína morfogenética óssea em fraturas distais de rádio-ulna de cão da raça Pinscher, demonstra-se a aplicabilidade desta técnica pelo que segue:

- O membro em que foi utilizada a proteína morfogenética óssea apresentou diminuição significativa do tempo de formação de calo ósseo.

- A proteína morfogenética óssea não causou nenhuma reação adversa no foco de aplicação do produto, do ponto de vista clínico, durante o período de observação.

Comparison between bone plate osteosinthesis and bone plate associated to bone morphogenetic protein in a bilateral distal fracture of radius and ulna in a dog - Case Report

\section{Abstract}

The aims and difficulties in small breed dogs radius and ulna fracture repair are known, frequently occurring cases of nonunionn principally in distal part of these bones, by their inherent anatomical
Key words:

Bone morphogenetic proteins. Radius. Ulna. Dogs.

Fracture fixation internal. 
characteristics, as poor muscular recovering, small medullar channel and less vascular aport, that are the principal causes of complication in post surgical or conservative procedures. By this reality, the comparison between treatment with bone plate and screws, with and without addition of bone morphogenetic protein (BMP), in distal fracture of radius and ulna in a Doberman Pinscher, cared in HOVET surgical area is described. It was evaluated the bone callus formation, by radiographic examination in $30^{\text {th }}, 60^{\text {th }}, 90^{\text {th }}$ and $120^{\text {th }}$ day of surgical procedure, being visualized total consolidation after 90 days in the control member and after 30 days in the BMP member, showing all the beneficial possibilities of the BMP use in cases of distal fractures in small breed dogs.

\section{Referências}

1 LAPPIN, M. R., et al. Fractures of the radius and ulna in the dog. Journal of the American Animal Hospital Association, v. 19, p. 643-650, 1983.

2 SUMNER-SMITH, G. Bone plating for radial fractures in small dogs. Modern Veterinary Practice, v. 3, p. 3033, 1970.

3 BELLAH, R. J. Use of a distal hook plate for treatment of a distal radial fracture in a dog. Veterinary Surgery, v. 16, n. 4 , p. 278-282, 1987.

4 DeANGELIS, M. P.; OLDS, R. B.; STOLL, S. G. Repair of fractures of the radius and ulna in small dogs. Journal of the American Animal Hospital Association, v. 19, p. 436-441, 1973

5 SUMNER-SMITH, G; CAWLEY, A. J. Nonunion of fractures in the dog. Journal of Small Animal Practice, v. 11, p. $311-325,1970$.

6 VAUGHAN, L. C. A clinical study of nonunion fractures in the dog. Journal of Small Animal Practice, v. 5 , n. 8, p. $173-177,1984$.

7 DENNY, H. R. Pectoral limb fractures. In: WHITTICK, W. G. Canine orthopedics. 2 ed. Philadelphia: Lea \& Febiger, 1990. p. 357-387.

8 EGGER, E. L. Fractures of the radius and ulna. In: SLATTER, D. Textbook of small animal surgery. 2. ed. Philadelphia: W. B. Saunders, 1993. p. 1736-1757

9 TURNER, M. T. Fractures of the bone of the front limb. In: OLMSTEAD, M. L. Small animal orthopedics. St. Louis: Mosby - year book, 1995. p. 205-208.

10 BOLANDER, M. E.; BALIAN, G. The use of demineralized bone matrix in the repair of segmental defects. Journal of Bone and Joint Surgery, v. 68-A, n. 8, p. $1264-1274,1986$

11 COOK, S. D.; WOLFE, M. W.; SALKELD, S. L.; RUEGER, D. C. Effect of recombinant human osteogenic protein-1 on healing of segmental defects in non-human primates. Journal of Bone and Joint Surgery, v. 77, p. 734-740, 1995

12 HECKMAN, J. D.; BOYAN, B. D.; AUFDEMORTE, T. B.; ABBOTT, J. T. The use of bone morphogenetic protein in the treatment of non-union in a canine model. Journal of Bone and Joint Surgery, v. 73-A, n. 5, p. 750-764, 1991.

13 HELM, G. A. et al. Utilization of type I collagen gel, demineralized bone matrix, and bone morphogenetic protein-2 to enhance autologous bone lumbar spinal fusion. Journal of Neurosurgery, v. 86, p. 93-100, 1997.

14 KIRKER-HEAD, C. A. Recombinant bone morphogenetic proteins: novel substances for enhancing bone healing. Veterinary Surgery, v. 24, p. 408-419, 1995.

15 MARTINEZ, S. A.; WALKER, T. Bone grafts. Veterinary Clinics of North America: Small Animal Practice, v. 29, n. 5, p. 1207-1219, 1999.

16 TORIUMI, D. M. et al. Mandibular reconstruction with a recombinant bone-inducting factor. Archive of Otolaryngology and Head Neck Surgery, v. 117, n. 10, p. 1101-1112, 1991.

17 TULI, S. M.; SINGH, A. D. The osteoinductive property of decalcified bone matrix - An experimental study. Journal of Bone and Joint Surgery, v. 60, n. 1, p. 116-123, 1978.

18 YASKO, A. W. et al. The healing of segmental bone defects, induced by recombinant human bone morphogenetic protein (rhBMP-2). Journal of Bone Joint Surgery, v. 74-A, n. 5, p. 659-670, 1992.

19 SKERRY, T. M. Fracture healing. In: COUGHLAN, A.; MILLER A. Manual of small animal fracture repair management. lowa: lowa State University Press, 1998. p. 29-34.

20 JONES, G. C. Imaging of fracture healing. In COUGHLAN, A.; MILLER A. Manual of small animal fracture repair management. lowa: lowa State University Press, 1998. p. 35-42. 
21 URIST, M. R. Bone: Formation by auto induction. Science, v. 150, p. 893-897, 1965.

22 FORELL, E. B; STRAW, R. C. Bone morphogenetic proteins and bone derived growth factors. Veterinary Comparative Orthopaedics and Traumatology, v. 6, p. 166-170, 1993.

23 LIND, M; ERIKSEN, E. F; BUNGER, C. Bone morphogenetic protein-2 but not bone morphogenetic protein- 4 and -6 stimulates chemotactic migration of human osteoblast, human marrow osteoblast, and U2OS cells. Bone, v. 18, p. 53-60, 1996.

24 EKELUND, A.; BROSJO, O.; NILSSON, O. Experimental induction of heterotopic bone. Clinical Orthopaedics, v. 263, p. 102, 1991.

25 GOLDSTON, R. T. Introdução e Revisão de Geriatria. In: GOLDSTON, R.T; HOSKINS, J.D. Geriatria e gerontologia do cão e do gato. São Paulo: Roca, 1999. cap 1.

26 BRINKER, W. O.; PIERMATEI, D. L.; FLO, G. L. Fraturas do radio e da ulna. In: BRINKER, W. O.; PIERMATEI, D. L.; FLO, G. L. Manual de ortopedia e tratamento das fraturas dos pequenos animais. São Paulo: Manole, 1999. p. 301-321. 